\title{
Evaluation of Palliative Care Implementation for Patients with Cancer at General Hospital of Dr. Kariadi, Semarang
}

\author{
Elisabeth Rosiska Purnamasari, Chriswardani Suryawati, Puji Harto
}

Master of Public Health, Universitas Diponegoro Semarang, Indonesia

E-mail: elisabeth.rosiska@gmail.com

\begin{abstract}
The prevalence of cancers increased up to 53\% from 2016 to 2018. Due to growing number of patients with cancer, palliative needs and end-of-life care also get increasing. Patients with cancer who received palliative care in 2017 were $3.42 \%$. This shows that cancer patients are not fulfilled the needs during hospital treatment, and some oncology specialists still handle without consul to the palliative team.

This study aims to evaluate of Palliative Care Implementation for patients with cancerat the General Hospital of Dr. Kariadi Semarang.

Qualitative research through case study approach was utilized. Eight respondents were used as sample. In-depth interviews and document analyses were the instrumens used.

The results show that no regulation is applied by palliative care teams, the organizational structure is not clear, the policy for palliative care is not integrated, and oncologists lack of commitment. Moreover, the funding for palliative team are not available, and the oncologists lack of collaboration and cooperation because they reluctantly refer a patient. The screening on standard assement is still inadequate for palliative patients with cancer. Moreover, there is no managerial supervision to follow up the palliative care. Education on patient prognosis delays because the doctor in charge do not give information as early as possible. Patient family feel satisfied about the palliative care for the psychological support and end-of-life care.

In conclusion, the palliative care implementation at the General Hospital of Dr Kariadi has not been integrated with oncology services. The oncologists lack of commitment, collaboration, and communication with providers.
\end{abstract}

Keywords-Evaluation, Palliative Care, Cancer.

\section{INTRODUCTION}

The General Hospital of Dr. Kariadi is a type-A teaching hospital in Semarang, giving healthcare services to community. This hospital is an excellent hospital for cancer treatment and becomes a role model in Indonesia. Based on data from medical records at the General Hospital of Dr. Kariadi, the prevalence of cancer in increased up to $53 \%$ from 2016 to 2018. Based on the demography data at the General Hospital of Dr. Kariadi, cancer is one of the ten highest diseases at inpatient unit in 2017 and 2018.

A palliative care program is an integrated approach to achieve good quality of patients' life and proper end-of-life. Also, it supports family who get depressed because of patient's condition through early detection, meticulous assessment, and ache treatment and other physical, psychological, and spiritual problems .(1)
Nowadays, palliative care in Indonesia are assumed only for patients who are metastatic and end their. (2).

However, a new concept about palliative care emphasizes on the importance of earlier palliative care integration, so physical, psychological, and spiritual problems can be wellsolved. Palliative care is holistic and integrated by involving inter professional, meaning that each patient has a right to be treated well for end-of-life.

Based on the prevalence reported by World Health Organization (WHO) in 2011, out of 29 billion cancers, 20.4 billion cancers need palliative care (3)

According to World Cancer Report in 2014, more than $90 \%$ of supports for reducing physical, psychological, and spiritual problems have been accomplished for patients with metastatic cancer through palliative cancer treatments.(4) 
The palliative care teams at the General Hospital of Dr. Kariadi Semarang have been formed and run since 2014. Palliative care should be linked with multidisciplinary to cooperatively give a personal treatment to palliative patients. Palliative care teams consist of doctors, nurses, psychologists, pharmacists, activists, as well as social and religious preachersfor terminal disease.(5)

Those approaches from multidisciplinary are usefulfor palliative care to improve the quality of patient's life mentally, physically, socially, and spiritually after the diagnosis. Such approaches are vital in the formulation of intervention on palliative care.(6)

Based on the preliminary interview with the informants, it was found that there are few referrals for patients with palliative cancer. Meanwhile, the documentations of palliative care teams show there were 31 patients with palliative cancer who consult to palliative care teams in 2017.The number of terminal cancers in 2017 is around 907 cases.It shows there are few referrals made by the oncologists to palliative care team is around $3,42 \%$, so it affects the success of palliative care implementation at the General Hospital of Dr. Kariadi Semarang.

The number of patients with metastatic cancer at the General Hospital of Dr. Kariadi Semarang was 907 patients in 2017. The high number of patients with cancer and metastatic cancer increases the palliative care and end of life care.(2)

According to Bainbridge et all, a system approach to evaluating a palliative care system uses a system of structures, processes, and outcomes (SPO), where the level of consideration is initially represented in the Donabedian SPO model. This systemapproach is used as research on the quality of health. (7)

This study aimed to evaluate palliative care implementation for patients with cancer, by evaluating the structure of the palliative care, namely organizational characteristics, such as organizational structure of the palliative team, policies and procedures related to plenary palliative care, as well as the commitment of oncologists and palliative team. Palliative process is evaluated from the characteristics of providers (interpersonal style of oncologists and palliative team), collaboration among providers, information, and organizational factors (managerial supervision on palliative care). Outcomes are the results of validation of the palliative care activities, including patient's family perceptions, patient family satisfaction, and perceptions of continuity.

\section{METHODOLOGY}

This study uses a qualitative research through case study approach and collects data through in-depth interview, unstructured interview with informants and document analysis.

The preliminary data were obtained from 8 informants, which consist of Medical Director, Head of Medical Division, Coordinator of Oncologists (Consultant Obstetrician Oncologist), a patient's relative, and palliative care teams (a palliative doctor, nurse, pharmacist and psychologist).

\section{RESULTS AND DISCUSSION}

\subsection{Organization Characteristics}

\subsubsection{Human Resources in Organizational Structure}

Human resource is an important component for the management to achieve the common goals. Bainbridge et all mentions that an organizational structure is a component that can show the obstacles in the system experienced by facilitators to achieve the organizational goals as effectively and optimally as possible for the process of palliative care.(7)

"There is no written regulation andno organizational structure with clear job description for palliative care team at the General Hospital of Dr. Kariadi Semarang”. (Key Informant 2, Palliative Nurse)

Based on the document search, only assignment letter of palliative team was found.

\subsubsection{Method (Palliative care Policy and Procedures)}

The palliative care at the General Hospital of Dr. Kariadi Semarang was firstly initiated by the management because it becomes the requirement of standard JCI (Joint Commision International) accreditation in providing end-oflife care.

"The policy in Kariadi Hospital is to provide palliative care near the end of life" (Key informant 1 and triangulated informant 3).

Policy and procedures will determine the goals and development of palliative care team in establishing a good structure for holistically palliative care. (7)

The General Hospital of Dr. Kariadi has not provided a policy for holistically integrated palliative care because they give end-of-life care near the death. Even though the end-oflife care is one of palliative cares, the palliative care is supposed to be given as early as possible and integrated to improve the quality of patient's life. 
Like Rudi's argument, a basic component for forming a palliative care team at a hospital is the support from the management, the availability of human resources, service priority, the availability of opioid analgesia, support and cooperation among stakeholders.(2)

\subsubsection{Material/Commitment among Providers}

Doctor's commitment especially oncologists' commitment should be maintained in providing palliative care for patients with cancer.

However, in fact, the oncologist' commitment in the implementation of palliative care is not optimal.

The palliative care team have run since 2014. Palliative care depends on the doctor in charge of patients. The doctor consults to the palliative care team when the patient with cancer is near to the end-of-life.

"Not involved in the preparation of end of life service policies. Disagree if end of life is palliative. Because there are palliative activities, take advantage of these activities, if there are patients who cannot be curative, I will consult the palliative team"

(Triangulated informan 3 , Coordinator of Oncologist)

"The palliative team is involved in the drafting of the end of life policy, even though the policy has not been holistic / plenary. Be involved in palliative services if there is a counselor from the DPJP oncology specialist"(Key Informan 1, Palliative Doctor)

Palliative Doctor, Palliative nurse, psychologist, and pharmacist are committed to run the palliative care program based on the procedures of end-of-life care at the General Hospital of Dr. Kariadi Semarang.

Only a few oncology specialists are committed to palliative care services, as evidenced by the very small amount of cancer patients who have been consulted to the palliative team. This proves that not all oncology spesialist are socialized.

Organizational commitment is a factor of team members needed to work together in a palliative care team.(8)

\subsection{Fconomic Factor}

\subsubsection{Financial Commitment}

Adequate resource and infrastructure are required to establish a continuous and adaptable program. Some vital assets include instruments, office rooms, technology, and finance.(7). Funding allocated for palliative care as needed can flourish the activeness of this program at the General Hospital of Dr. Kariadi Semarang.
"Financial commitment for developing the palliative team is not optimal. If there is a proposal, the management will handle it" (Key Informant 2, Palliative Nurse).

"There is no specific budget for the palliative team, if there is a proposal for submission to management it will be facilitated"

(Triangulated informan 2, Head of Medical Divison)

Based on in-depth interviews it was found that there was no specific budget for developing palliative care services. During this time, if there is a proposal submission from the palliative team, it will be facilitated by management.

\subsection{Service Process}

\subsubsection{The Interpesonel Style for Palliative Care}

It was found that the interpersonal style of the oncologists has not supported the palliative care because they still apply Solo Congres Model. In the model, the doctor in charge of patient handles the palliative patient alone, but they do not collaborate with the palliative care provided. Not all palliative oncologists integrate the end-of-life care to the palliative care team.

Interpersonal style is professionalism between members which ultimately determines the extent to which professionals are able to cooperate in palliative services.(7) The presence of professional style in the palliative service model is an approach to providing the best quality, right and effective service, and reducing overlapping, duplication and gaps in care, especially palliative care at General Hospital of Dr. Kariadi Semarang.

A study done by David Hui Bruera states that Integrated Care Model is recommended because the standard palliative care is comprehensively carried out on time with proper oncology treatment. This model also can make palliative care easily introduced, and lets the oncologists provide the high quality of treatment. (9)

The oncologist can handle various problems which need special supporting treatment.It is in line with what the informant said.

Based on in-depth interview triangulation informant $2 . \mathrm{He}$ worked as a Head of Medical Division. He said "There are still no common goals about the palliative care done by the oncologist since they think they have competency on palliative care."

"When a patient with cancer is re-radiated, it means palliative. What's the purpose of being referred to palliative pediatrician? It's better if I handle it by myself"'(Triangulation informant 3, Oncology Coordinator). 
"It is not optimal yet. Not all oncologists refer patients with cancer to be given a palliative care". The palliative care has not been integrated to the oncology care because the oncologists handle the treatment by themselves or just consult the patients who are near the end of life" (Key Informant 1, Palliative Doctor).

Based on the interview, it can be concluded that the interpersonal style of palliative care team is good since they work together. Meanwhile, the interpersonal style of the oncologists is not supportive and collaborative. It occurs because they have different definitions of palliative care, so they are reluctant to refer a patient to the palliative care team.

\subsubsection{Collaboration among Providers (Oncologists and Palliative Care Team)}

Emily Lai defines a collaboration as team involvement to coordinately solve a problem together. Collaborative interaction can be seen from whether the team have common goals, commitment and dependency. (10)

The palliative care team at the hos pital lack of collaboration. Some arguments from the informants support this fact.

He worked as a Medical Director. He said "The palliative care team rarely collaborate with the oncologists" (Triangulated informant 1, Medical Director).

Based on the argument above, they have poor commitment and communication. Weak collaboration may cause the palliative care program under standard.

Collaboration can speed the team to achieve their common goal even dividing tasks to individuals is not recommended during this process. (10)

From the interview, the goals and values of the palliative doctors, palliative nurses, pharmacists, and psychologists are the same.

'It's to improve the quality of patient's life, so patient's needs are fulfilled. Offering comfort for patients can be done through spiritual, mental, and social guide and support. This is done to relieve the burden of patient and their relatives by giving some therapy needed and controlling symptoms. Thus, patients will end their life with dignity"

(Key Informant 1, Palliative Doctor)

Collaborative approach should be applied in the palliative care where interprofessional expertise is required to handle various patients' needs.(11)

Overall, team commitment to collaborate and provide extensive treatment is the important factor in a team.(12)

\subsection{Information}

\subsubsection{Communication and standard assesment on Patients' Needs}

Communication covers all aspects in the providers who interact mostly with patients. Some stimulating activities among inter professional like a formal or informal interdisciplinary forum vitally create collaboration among individuals in organizations to perform excellent palliative care. (13)

The forum for the palliative care team has worked well even though it is not regular. However, communication with the management is in form of a monthly report about the referrals of palliative patients. Regular meetings with the oncologists have not been done.

The standard assessment on patient's needs shows that the clinical tools are required, and the palliative care instrument PPS (Performance Palliative Scale) is also necessary. Performance palliative scale is a modified version of karnofsky performance scale for palliative care.

However, in fact, the hospital does not have a screening tool for palliative referrals that needs to be consulted. The doctors only consult patients who are near the end of life to the palliative team care. The informant's argument supports this finding.

"No screening for referred patient with cancer from the doctors in charge. If the hospital provides, it will be better. It can be karnofsky perfromance scale / Performance Palliative Scale / ECOG” (Key Informant 1).

According to David Hui, there are many reasons why the oncologists are reluctant to refer patients, including worries for disturbing patients, considering a referral as a failure, and hardly understanding the usefulnes s of referral. Most of them do not understand that palliative care can be mutually given along with the directed therapy (9).

\subsection{Organizational Factor}

\subsubsection{Management Supervision about Palliative Care at the General Hospital of Dr. Kariadi Semarang}

The supervision done by the management on the implementation of palliative care is lacking, so the program cannot achieve the goals well. The success of supervision is caused by several components, such as good organizational structure, work procedures, and work plan.(7)

"The palliative care has been socialized, and there must be follow up. However, the management do not do it regularly 
even no monitoring and evaluation on the palliative care at the hospital." (Key Informant 1, Palliative Doctor)

"Palliative care service at the hospital is not regularly monitored by the management." (Triangulation Informant 1, Medical Director)

\subsection{OUTCOME}

\subsubsection{Client Perception}

The hospital needs to shape client perception that the palliative care is valuable and necessary. In fact, the hospital has not educated their clients about the usefulness of palliative care. Perception is the validity of palliative care that has been run. (14)

"Until now, as a husband and child, I think information about palliative care is still weak. The doctors in charge do not give information as early as possible. Information about prognosis and patient condition is delivered by the palliative doctors. The palliative team have conducted a family meeting for explaining patient's condition, prognosis, and progress to the relatives"'(Triangulation Informants 4,patients relative).

\subsubsection{Satisfaction about Treatment and Access}

Client satisfaction is a happy or sad feeling about goods or services that people have expectations before use it.(15)

"I am satisfied about the availability of treatment as my mother stays in hospital. Access to information is good, and the doctor palliative explains clearly. However, on the other side, I am also dissatisfied about psychological support and treatment. It is not optimal even though my mother can do nothing. It's better to inform us that my mom suffers a cancer as early as possible"(Triangulation Informant 4, patients relative).

\subsubsection{Perception about Treatment Continuity}

Based on the interview with the key informant 1, it is expected that palliative care team can be integrated with the oncology team.

"During my stay at the General Hospital of Dr. Kariadi Semarang, the treatment has been optimally given, and it is good, I think. However, the doctors did not inform us as early as possible. As a husband and son, after the palliative team (palliative doctor) explained to me, I knew the future prognosis. We need to be mentally and physically ready for that. I hope my mom ends her life peacefully. I hope all patients with cancer like my wife and mom can receive early palliative care"

(Triangulation Informant 4,patients relative).

Continuity is considered as providing a treatment from interprofessional with coherent, logical, and punctual procedure.(11)

\section{CONCLUSION}

To conclude, this study discovers that an integrated palliative care for patients with cancer at the General Hospital of Dr. Kariadi Semarang is not optimal. The Hospital should improve the integrated palliative care to properly fulfill patients' needs through clear regulation and organizational structure, integrated and holistic policy, strong commitment of the providers, strong collaboration, well-delivered information and management supervision. Ultimately, these efforts can result in satisfying outcome for patient's family.

\section{ACKNOWLEDGEMENT}

We thanked the General Hospital of Dr. Kariadi Semarang for giving permission in conducting this study.

\section{REFERENCES}

[1] Kemenkes. Pedoman teknis pelay anan paliatif kanker. 2013.

[2] Putranto R. Peran Internist dalam Membangun Layanan Paliatif di Rumah Sakit. 2015;

[3] World Health Organization. Knowledge into Action Palliative Care Cancer Control Knowledge into Action Palliative Care. 2007.

[4] World Health Organization. World Health Organization International Agency for Research on Cancer; Globogan 2013;Estimated cancer incident, mortality and prevalence worldwide in 2013 [Internet]. Vol. 4, World cancer report. 2014. 54-68 p. Available from: http://scholar.google.com.scihub.io/scholar?q=Transitions in human development and the global cancer burden In Wild CP Stewart B Eds World Cancer Report\#0

[5] Kemenkes. Modul TOT Paliatif Kanker. 2016. 1-21 p.

[6] Rudi Putranto, Laksono Trisnantoro YH. Penghematan Biay a Perawatan Pasien Kanker Terminal Dewasa melalui Konsultasi Tim Paliatif di Rumah Sakit. 2017;4(1):36-41.

[7] Bainbridge $D$ et all. A proposed systems approach to the evaluation of integrated palliative care. 2010;

[8] Bhatt A, Mitchell A. Palliative Medicine \& Care: Open Access Effective Collaborative Communication in Hospice Care. Palliat Med Care. 2015;2(1):1-13.

[9] Hui D, Bruera E. Model Oncology and palliative care. 2015;4(3):89-98.

[10] Lai ER. Collaboration: A Literature Review Research Report. 
2011;(June).

[11] Morley L, Mrt T, Cashell A, Mrt T. Collaboration in Health Care. J Med Imaging Radiat Sci [Internet]. 2017;48(2):20716. Available from: http://dx.doi.org/10.1016/j.jmir.2017.02.071

[12] Hawley P. Barriers to Access to Palliative Care. 2017;

[13] Boyle D. Palliative Care Communication in the ICU: Implications for an Oncology-Critical Care Nursing Partnership. Semin Oncol Nurs. 2017;33(5):544-54.

[14] Shaller D. Apa yang dibutuhkan? Dale Shaller Shaller Consulting Oktober 2007. 2007;

[15] Anjarryani WD. Kepuasan pasien rawat inap terhadap pelay anan perawat di rsud tugurejo semarang. 2009; 